${ }^{1}$ Department of Occupational Therapy, School of Health Sciences, University of Western Macedonia, Greece

2Department of Psychology, Sport, and Geography, University of Hertfordshire, UK ${ }^{3}$ Hertfordshire Partnership University NHS Foundation Trust, UK

Corresponding author: Konstantinos Georgiou $\mathrm{PhD}$, Department of Occupational Therapy, School of Health Sciences, University of Western Macedonia, Papagou 41, Veria Greece, 59100, Tel:+30 6974359695, email: gioukon@gmail.com, orchid ID: https://orchid. org/0000-0001-64224255

\title{
"But Who Knows What Autism Is?" Negotiating the Notion of Autism During Free Associative Narrative Interviews with Psychoanalytic Psychotherapists
}

\author{
Konstantinos Georgiou ${ }^{1}$, David Winter ${ }^{2}$, Stephen Davies $^{3}$, Aikaterini Katsiana ${ }^{1}$
}

\begin{abstract}
Background: Critically informed discursive research has rarely been used to capture the way psychoanalytic psychotherapists organize their talk with regards to Autism Spectrum Disorders (ASD). Objective: To understand the language about autism in psychoanalytic talk in terms of i) interpretive repertoires, ii) subject positions and iii) autistic ways of being that circulate inside psychoanalysts' discourses. Methods: This paper presents the data and findings of a critical discursive psychological research which analyzed the talk of eight experienced psychoanalysts. As part of a wider research project this study strived to provide an understanding of the way autism was deployed in free associative narrative interviews. Results: Focusing on the micro and the macro level of discourse, the analysis of the data pointed to a rather dilemmatic framework mobilizing therapeutic talk. This framework was organised around a quadrant of interpretive repertoires, which on the one hand fought against the traditional medicalized discourses about autism, while on the other repositioned autism in the same subordinate positions crafted by biomedical regimes. Conclusion: A need for breaking from this rather malleable discursive ecosystem is advocated in order to give life to a more democratic let alone emancipating clinical and political environment. Keywords: Autism, Psychoanalysis, Disability Politics, Critical Discursive Psychology.
\end{abstract}

\section{BACKGROUND}

The current paper is part of a wider project that concerned the constructionist understanding of the phenomenon of autism spectrum disorders in clinical and non-clinical social environments (1-5). In line with the recent trends in the social sciences which understand psychotherapy as a dialogical phenomenon (6-12). This paper portrays autism as a fluid construction which takes place inside the premises of a complex discursive ecosystem. It particularly concerns the way in which the notion of autism is negotiated in psychoanalytic psychotherapists' talk during unstructured conversations (13-21).

Research about autism has been dominated by traditional methods which, as argued by Lester (22), regularly draw from an etic rather than an emic perspective. Clearly, much of the research about autism is deficit-oriented. This reflects a wider tendency inside the scientific community which focuses on the etiological and thus mechanistic understanding of the condition through quantitative methodologies. It also explains the relative marginalization of qualitative designs, despite the fact that current accounts speak of their value in interrogating issues of subjectification and identity construction (21-26).

This paper then reports the findings of a critical discursive psychological (CDP) analysis of the psychoanalytic psychotherapists' talk about their work with autistic individuals. Two broad sets of research questions informed the conduct of this research: a) The first set drew form the 
macro level of language, questioning the way autism was constructed in psychoanalytic talk and also issues of subject positioning and the ways of being that were enabled or constrained through them. b) The second array of questioning was guided by the micro-level of interaction in an effort to understand the way the different interpretive repertoires appearing in the conversation allowed.

\section{OBJECTIVE}

To understand the language about autism in psychoanalytic talk in terms of i) interpretive repertoires, ii) subject positions and iii) autistic ways of being that circulate inside psychoanalysts' discourses. the therapists to attain specific interactional and rhetorical goals.

\section{MATERIAL AND METHODS}

The critical discursive psychological (CDP) framework utilized in this research was initially advocated by Potter \& Wetherell (27) and later modified by McAvoy (2015). Originally, Wetherell tried to address CDP as: 'the capturing of the paradoxical relationship that exists between discourse and the speaking subject' (p. 4). This variant of discourse analytic research tries to overcome the dualistic deployment which crosses the broader discourse analytic literature (28-35). Inspired by the different traditions of discourse analysis, the employment of CDP in this study allowed for a performative consideration of autism (8) in two central respects: a) as an interactional accomplishment between the therapist and the interviewer and $b$ ) as determined by the wider cultural resources that organized the unfolding dialogue.

Within therapy and research, discourse analysis has provided an alternative way of inquiry $(2,4)$, involving a novel understanding of intersubjective experience which mainly relies on language use. In the current research, it employed a hierarchical conceptual model to consider therapeutic language about autism as: 1) Constructive; 2) Functional; 3) Producing specific subject positions; 4) An instrument of power; 5) Producing different types of subjectivity (3).

\section{Methods}

The dynamic strategy selected for generating data resulted in the recruitment of 15 potential research participants. From them seven female and one male therapist were recruited according to the inclusion criteria which included a) having at least 10 years of practice with autistic individuals, b) fluency in English, c) if retired, continuing active involvement in the field such as supervision or teaching. The mean age of the sample was 53 years old, six of the therapists were employed in the public sector while two of them were practicing psychoanalysis privately.

The interviews, which used a free associative and narrative theoretical framework FANI (18), were conducted in settings chosen by the participants and lasted from 60 to 90 minutes. Every participant received a transcript of their interview with the option of modifying this. All data were subjected to discursive analysis by the principal researcher as described by Potter and Wetherell (27) and Harper (17).

\section{RESEARCH FINDINGS}

The findings of the critical discursive analysis revealed four inter-related interpretive repertoires as part of a fluid dialogical landscape.

Repertoire 1. Autism as an unknowable construct

The first repertoire reflected the therapists' ontological concerns about autism. As shown in the data quoted it appeared early in the conversational flow of most of the therapists, through an emphasis on notions of unknowability and variability.

For example, Hannah (see Table 1) questioned the psychiatric diagnostic regimen early in her interview. The idea of autism as not being easily detectable and also involving a disturbing variability is apparent in this piece of talk. The therapist represents herself through the catch pole metaphor which provides autism with a very distinctive, let alone dysfunctional, flavoring. Historical accounts appraised autism though the primitive functioning rationale, which secondarily impacted negatively on separate individuals (13). Two main attributes characterize autism through this metaphoric plane, a) the undisciplined, 'feral' qualities of the individual and b) its slippery nature that needs to be gleaned through the practitioner's expertise. In both senses the condition is closely related to a discourse of monstrosity which further connotes a close relationship among autism and carnal ways of being (36)

The therapist in this vignette seems torn by the diagnostic variability of autism. While she presents herself as capable of diagnostically identifying autism, she also resorts to several discursive devices which counter her core argument. Initially, the use of the small clause 'the thing called autism' (line 4) weakens the diagnostic imperative. Then she keeps moderating the argument by utilizing a quantifier 'a lot of the children' (line 6) while resorting to the use of the passive voice 'happened to have a diagnosis of autism' (line 6). The use of hedging in line 7, 'is probably what I would think of', epitomizes the therapist's agonizing state with regards to the clinical identification of autism.

In the next extract (see Table 2), the dilemmatic framework is exacerbated through the articulation of the experiential versus diagnostic understanding of autism. The participant, Sofia, could be seen as unintentional recycling the dichotomized understanding which saturates the language of autism and disability $(15,25)$. While she sets up an ideological battlefield (9), she mobilizes a number of rhetorical commonplaces (7) attempting to establish the enigmatic and thus 'unknowable' construction of autism. Yergeau (39) has pointed out that autistic individuals have been persistently described through discourses of unknowability. Through narratives which represent them as tragic or abject, they are stripped of their ability to set up their own meaning frameworks and are therefore regulated by the authoritative practices of the experts.

Indeed, in this extract the participant carefully develops her contradiction to the mainstream discourse that surrounds the diagnostic language of autism. She assembles her criticism by the use of a cognitivist accounting through the repeated use of 'I don't know' (lines 7-11) and also 'I understand' while simultaneously providing an emotional quality to her statement through the use of 'I can't 
1 R: So (.) in terms of my wo:rk actually with each individual patient (.) 2 it:s very different /

3 So I think my experience of autism as a kind of catchpole (.) 4

cause I don't really believe that the thing called autism in the singular sense (.) 5 is you know kind of I sup:pose (1.5)

6 in the (.) that in a lot of the children that I worked happened to have a diagnosis of autism

7 is probably what I would think of (1.5)

Table 1. Therapist Hanna

6 because for me if you ask me what autism is (.) or how I under-

stand it

7 I can honestly tell you I don't know

8 if I have to go by diagnosis /

9 because the children that I have seen (.) and were diagnosed by pediatricians and psychiatrists er $(0.8)$

10 were so different and the level over which they were reaching you know (.)

11 the level of the three diagnostic < d don't know what the word is $>$ ...

16 the possibility to make a real emotional connection with the child

17 was worthily different and that the child $=$

18 =and that with some children on the diagnosis (.)

19 I really can't feel that they don't want contact

20 that they withdraw that they try to avoid it

21 that it feels uncomfortable or even painful for them /

22 and I have seen children in therapy you know (0.9) with the

diagnosis

23 who really want to make a connection

24 who engaged with me (0.6)

25 which to me I don't think it's autistic /

Table 2. Therapist Sofia

feel' (line 19). In this way she inhabits a personal opinion framework to distance herself form the vagueness of the diagnostic attitude.

Repertoire 2: Autism as defence/safety

While the first repertoire circulated around the enigmatic nature of autistic life, the second one encapsulated the widespread idea of autism as a reaction to the interpersonal field coupled with an association between defence, individual security and worthwhile living. The dualist deployment of the defense safety repertoire was informed by the $20^{\text {th }}$, century developmental language which involving a dichotomy between social and individual levels of being.

In the vignette presented in Table 3, Muddy mobilizes the defense safety repertoire in order to account for her experience of an autistic child. She initiates her talk by subscribing to developmental language through the use of the modal 'could' (line 1) foregrounding the subsequent conversation. Muddy is confronted with the delicate business of reporting a personal experience of a therapeutic relationship and she thus resorts to an 'eye witness' layout to achieve this (26). She structures her argument through an interplay between a) pronoun reversal (line 9, line 11), b) reported speech (line 9) and c) a contrast between detailed and vague narrative which provides the text with a style of vivid description.

Unlike Muddy the therapists in the extracts presented in Tables 4 and 5, Elizabeth and Hannah, conflate the defense/ safety repertoire in a different fashion. Characteristically, both accounts position the child as actively resisting against his/her therapist. Neither Hanna nor Elizabeth subscribe to autism as lacking sociality, as many contemporary developmental scientists would. On the contrary, they see the
$1 \mathrm{R}:$ He could imagine being a school teacher (.)

2 and I was the student (.)

3 and I got punishments for writing the same thing many many

hundreds of times when I did

wrong things

4 And the wrong things were talking to him about things I shouldn't talk about /

5 I: Like what?

6 R: like gaps (.) like why he always had to have a calendar (.) 7 like why we had to play the same boring game

8 every time we didn't do anything new (.) and like when he put a notice up he said (1.7)

9 you r going to do handwriting practice today (.) ....20 so I said, 'I think born is when people are born and I think you are saying (.)

21 people aren't allowed to be born they are not allowed to go out, it would be dangerous' /

22 I think (.) I was a bit direct about it (.)

23 that you are not allowed to come out into a different sort of world when you talk to me

and we can play (2.5)

24 and he said now you have to write that up nineteen nine hundred times (1.3)

$26 \mathrm{I}: \mathrm{Hm}$ (laughter) (.) so this is your punishment /

$27 \mathrm{R}$ : and there is to be no change, there is to be no change

28 he then said, you are not allowed to go out to play

29 so I begun to see that there was some kind of structure in him (.)

30 which did not allow certain things which were too dangerous

Table 3. Therapist Muddy

1R: I can:no see (.) how (1.1) you cannot have a relationship

2 I can see how you can withdraw from it /

$3 n>\mid$ can see< how you can wit:hdraw from it because of physical trauma (.)

4 because of being born too early (.) 5 of being left in an incubator

Table 4. Therapist Elisabeth

child as intentionally performing an interactional barrier towards external reality. They therefore pronounce an alternative paradigm with regards to autistic social deficits which is less taken to be the result of faulty wiring. In this way they replace traditional theoretical accounts with a relational language in order to explain the children's social defects. The result is paramount, for it creates the kind of subject positioning which is based on the familiar power dynamics that exist in western therapeutic establishments (29).

Repertoire 3. Autism as malignant state of being

Most of the therapists employed some version of the third variant of discourse. Inside it, autism is bound up through a tripartite structure which resembles a cancerous state of being. There is a) an insistence on the damaging effects of the condition for the suffering person, presenting similarities with people suffering from a terminal illness; b) presentation of the condition as a disturbance of the normative progression of life: and c) as a toxic contaminant of social life that could compromise the mental integrity of the therapist. In a similar fashion to Tantam (33), who utilized the linguistic resource of malignancy to describe autistic individuals, most analysts drew on such language to i) emphasize the autistic person's fragility, ii) to enhance the effectiveness and the restorative role of therapeutic intervention and iii) to positively construct their healing identities.

In the passages presented in Table 6, Christine employs a highly emotive language in order to build an account of autism as a malignant state of being. By sequencing her ac- 


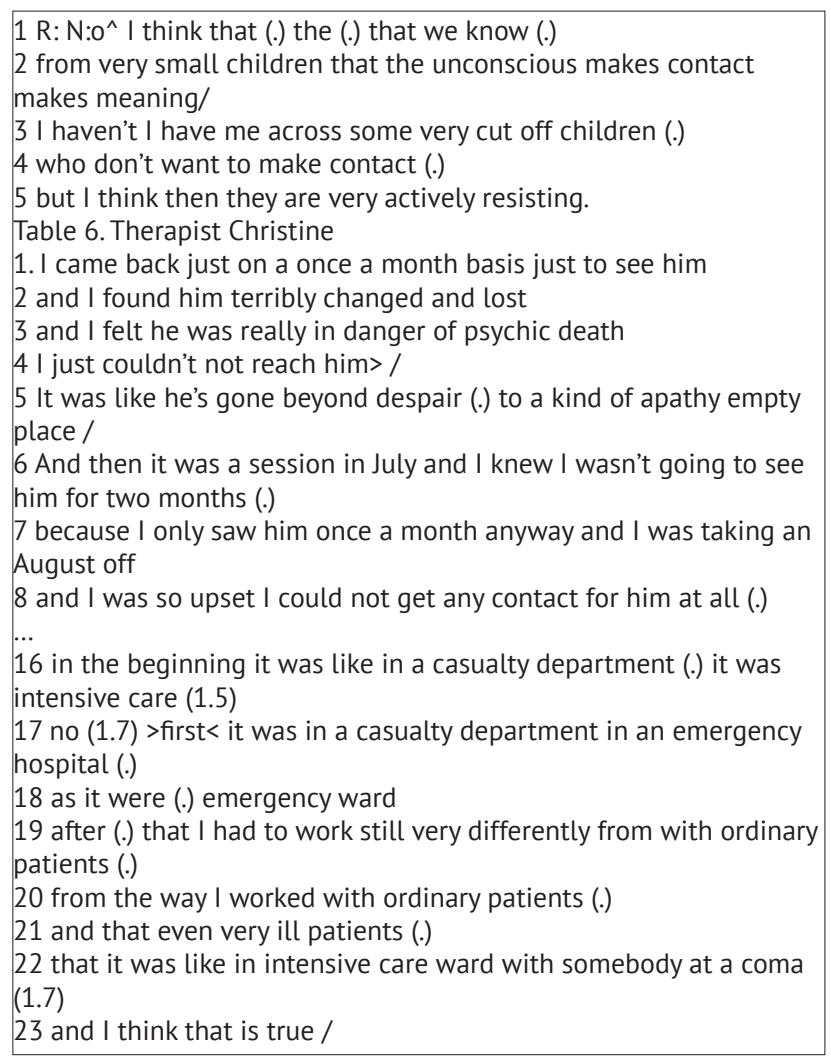

Table 5. Therapist Hanna

count through successive extreme case formulations, she manages to present this case as something exceptional. The use of extreme case formulation has been regularly studied in the interactional context. Most authors argue that these language devices are utilized in order to provide emphasis and particular interest in dialogue (10). Christine could be seen as using these devices as in line 2-3, 'I came back just on a once a month basis just to see him and I found him terribly changed and lost', and 'I felt he was really in danger of psychic death I just couldn't reach him' (line 4) and 'was like he's gone beyond despair, to a kind of' (line 5) to build a distinctive case of a person suffering from a life risk disorder. At the same time the use of the three consecutive clauses constructs a three-part structure which, according to Antaki and Wetherell (1), is capable of serving the rhetorical pursuits of the speaker. Within this framework, Christine manages to empower her position inside the conversational apparatus without allowing the interviewer to counter her personal opinion framework.

In the passage provided in Table 7, Nicky, provides an alternative to the discourse of malignancy. Instead of presenting the person as someone who is at life risk, she provides a relational basis for the condition by mobilizing a description of autism as toxic. She therefore orients her talk through a negative appraisal, 'paralyzing effect on the therapist' (line 2), while she tries to present herself as someone who is not telling tall stories (11). In this way she builds an ordinary accountability (31) from which she can go on crafting her own version of autism. This version is built on the grounds of vivid recollection which mainly relies on a granular description of the bodily encounters between the child and the therapist such as in 'open his box' (line 5), 'I got moving again' (line 19) and 'something active to do'
$1 \mathrm{R}:$ and (.) em (.) $\mathrm{h} \mathrm{h}$

2 some children on the spectrum can have a very paralyzing effect on the therapist actually

3 I mean I remember> the worst one I ever had (.)

4 was somebody [laughs] where l'd go along (.)

5 and open his box and he'd come along and shut his box (.)

6 and that was that was that and for quite time/ apathy, empty place (line 5)

...

19 so I got moving again and I was absolutely staggered when I realized (.)

20 that he'd been standing there watching like this> until I started moving again (.)

21 and then he moved (..)

22 and I thought my goodness this is felt so controlling and so such a prohibition (.)

23 that actually this child is completely geared to me /

24 And I th o you know I mean he waited while I waited and he moved a bit when I moved

25 and I thought my goodness (.)

26 this is a completely different experience from how l've been interpreting it /

27 and that was quite fortuitous you know (.) ....

34 A lot of them you see (.)

46 do have that effect on you (.)

47 because since you are talking about being active

48 in order to be active you have to think of something active to do (.)

49 and some of them have this effect on you that you <can't think of anything whatsoever at all>

50 you know /

\section{Table 7. Therapist Nicky}

\section{R: Well I mean simply (.) I suppose very simply (.)}

2 they don't feel (.) a lot of them (.) <that they can rely on their body> (.)

3 to stay together in one piece /

4 um and it can feel as though a bit just come off you know (.) .....

15 I mean of course it hadn't come off

16 but the >point is< she kept> (1.1) she didn't feel it (0.9) was really her (.) her emotional possession

Table 8. Therapist Sofia
1 I mean they were autistic and they were psychotic (.)
2 people don't say psychotic now (.)
3 but (.) u:m (0.9) I mean (.) I remember one little girl
4 who would be sitting in the circle on the mat
5 and she just suddenly screamed and get up
6 and go crouching the corner and urinate for no reason
7 it was $(0.8)$
8 I mean of <course> there is rea:son (.) that was to do with what was happening inside her
9 not anything to do with what was happening in the room /

Table 9. Therapist Sofia

(line 48). Nicky's account therefore differs significantly in that it repositions the child in a relational template which results in two separate subjectivities: a) the child as an infectious and controlling being; b) the therapist as a powerless victim against the controlling character of the child.

Repertoire 4. Autism as disabled embodied materiality

The final repertoire is deeply rooted inside the idea of bodily dysfunction as a way of understanding and also explaining the autistic condition. Most of the therapists used the disabled embodied materiality discourse to account for the person's impaired functioning and also to orchestrate 
the person's body through normative locomotive practices (16). Interestingly, the autistic body became the terrain of embodied disablement and also the place where most therapists tried to exert their ideological imperialism (39). As Thomson (34) argued, disability relates to the articulation of the deviant characteristics of the body.

In the piece of talk provided in Table 8, Sofia launches a negative assessment about the child's embodiment, based on a modernized perception of the body and through a damaging metaphor (36). She emphasizes aspects of bodily integration which connote reduced agency over the body. In this way she treats it as the locus of disablement without reflexively voicing her own participation in the disabling process. Turner (35) used the notion of 'somatic society' to refer to those regulatory activities which monitor and shape embodied practices in modern societies. In Turner's terms, the therapist could be seen as enacting a form of bio-power which gives her the authority to regulate the conduct of the child's body.

In a subsequent piece of talk (Table 9), Sofia continues with her elaboration of the autistic body. What is striking in this account is the therapist's attempt to provide an explanation of the child's disorganized bodily conduct. Initially, she colors the activity as irrational (lines 5-6) but she quickly softens this negative assessment by stating that 'I mean of course there is reason' (line 8). The therapist's oscillation between two contrasting formulations reveals her getting caught in the delicate business of meaningfully explaining autistic behavior. While she tries to resist talking about autistic behavior as meaningless, she cannot break away from the dysfunctional view of autistic embodiment. In this manner, she reproduces the conventional ways of materializing the autistic body which consists in scripting the body against chaotic events that become human embodiment through cultural signification. Yergeau (39) poignantly referred to the negative implementation of the autistic body through hegemonic language and rhetoric when she stated: "Tie me to a gurney. The gurney is more material than I am' (p. 253).

\section{DISCUSSION}

The analysis of the therapists' talk exemplified how they rhetorically structured their conversations in order to navigate a notably dilemmatic framework. This framework was characterized by two main orientations. On the one hand, the therapists enacted an egalitarian attitude where they tried to redefine the notion of autism against the mainstream psychiatric constructions (2). On the other hand, they reproduced the hegemonic framework surrounding autism which is maintained through the emphasis on pathologization and medicalization (21). As a result, autism appeared paradoxically situated among two polarized metaphorical planes. First, it was woven as a condition that does not necessarily align with the traditional ways in which it has been treated by the scientific biomedical regimen. Second, it was fabricated as a rather problematic form of life that requires sophisticated remediation in order to resume its normative trajectory and overcome its malleable characteristics (24). Overall, the repertoires presented constituted an inconsistent and polarized discursive field which, according to Billig et al. (7), secures the 'attitudes of the healthy toward the ill' (p. 94).

The use of the first repertoire aligned with those cultural voices that place an increased emphasis on the enigmatic nature of the condition. Murray (25) opined that autism is regularly represented as a kind of unresolved puzzle. Similarly, Roque (28) and Waltz (36) opined that autism has been elaborated as a mysterious entity in Western society. Lester (22) emphasized the way parents and therapists of autistic individuals drew on such language as a way to positively appraise autism. In contrast, the participants in the current research utilized the discourse of unknowability to connote negative qualities of the autistic individual through equating the meaning of variability to unknowability. Unknowability then became a discursive strategy which on the one hand positioned the autistic subject in a state of non-existence while on the other it legitimized the therapists in creating stories for the 'unknowable' (16). At the micro level, unknowability became a flexible linguistic resource, allowing the therapists to introduce their own deficit-laden rhetorical agendas.

The three contrasting repertoires then invested in a language that recycled the pathological conceptualization of autism. Beginning with the repertoire of defence/safety, most of the therapists emphasized the idea of a social disorganization. One of the main characteristics of the second repertoire related to the employment of a militant discourse based on notions of interpersonal aggression and relational control, which through the use of the 'eye witness' reporting succeeded in building robust therapeutic storylines. Through an emotional vocabulary, the third repertoire deepened the sense of disorder around autism. Grounded in the metaphor of a comatose condition, it conflated autism either as a risk to life itself or a toxic contaminant for the other person. Finally, though discrete embodied scenarios the disabled embodied materiality repertoire placed autism in the trajectory of disabling corporeality and disembodied sociality.

Goodley (14) questioned the pathologizing tendency that diachronically informs the discourses about disability. In a similar vein, Yergeau (39) openly addressed the present dilemma cutting through the autistic universe when she stated: 'who defines better? To whom do we listen, the autistic or the non-autistic?' (p. 4). In the same fashion, this research showed that through the interplay of the four interpretive repertoires, the therapists secured their authoritative roles while delimiting autism to a way of being that required repair and sophisticated treatment. In this manner, the therapists aligned with those political imperatives that on the one hand appear sympathetic to the idea of living with autism but on the other try to mitigate it (24).

\section{CONCLUSION}

It could be stated that while this research draws attention to the dilemmatic description of autism in psychoanalytic language, it also mobilizes the need for breaking away from this in clinical environments. The clinical significance of the research findings relates to the apparent impossibility of understanding autism outside the polarized and conflictual discursive network. The notion of autism is encapsulated 
in oppositional constructions which function like borders of subjectivity. In this vein, it becomes unthinkable to consider the nature of the condition outside these thinking apparatuses. This apparently neo-liberal political context demands that one is unable to exist outside the discursive ecosystem crafted by pathology (30). Perhaps the only escape from it is to resort to a state of non-existence and 'unknowability'. In this sense, autistic people could be seen as always dislocated by the paralyzing dilemma implicitly imposed on them though this discursive framework, epitomized in the clause: 'should I strive for normality, or should I die instead' (12).

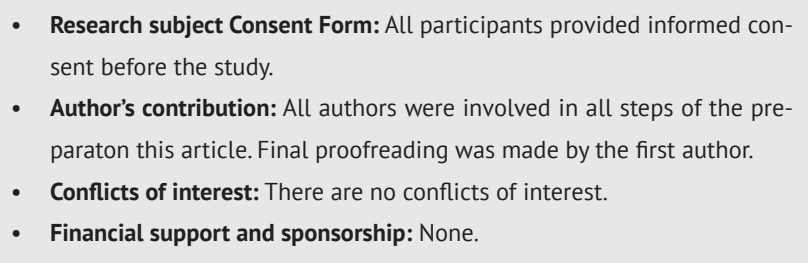

\section{REFERENCES}

1. Antaki C, Wetherell M. Show concessions. Discourse studies. 1999; 1(1): 7-27.

2. Avdi E. Exploring the contribution of subject positioning to studying therapy as a dialogical enterprise. International Journal for Dialogical Science. 2012; 6(1): 61-79.

3. Avdi E, Georgaca, E. Researching the discursive construction of subjectivity in psychotherapy. In: Smoliak O Strong T. (eds.) Therapy as discourse: Practice and research. Palgrave / Macmillan; 2018: 45-69.

4. Barad H. Meeting the Universe Halfway: Quantum physics and the entanglement of matter and meaning. Duke University Press; 2007.

5. Billig M. The dialogic unconscious: Psychoanalysis, discursive psychology and the nature of repression. British Journal of Social Psychology. 1997; 36(2): 139-159.

6. Billig M. Rhetorical and discursive analysis: how families talk about the royal family. In: Hayes N. (ed.) Doing Qualitative Analysis in Psychology. Hove: Psychology Press; 1997: 39-54.

7. Billig M. Condor S. Edwards D. Gane, M. Middleton D. Radley A. Ideological dilemmas: A social psychology of everyday thinking. Sage Publications, Inc; 1998.

8. Butler J. Gender trouble. New York: Routledge; 1990.

9. Edley N. Analysing masculinity: Interpretative repertoires, ideological dilemmas and subject positions. In: Wetherell M. Taylor ST. Yates SJ. (eds.) Discourse as Data: A Guide for Analysis. London: Sage; 2001: 189-128.

10. Edwards. D. Extreme case formulations: Softeners, investment, and doing nonliteral. Research in Language and Social Interaction. 2000; 33(4): 347-373.

11. Edwards, D. Managing subjectivity in talk. In: Hepburn A. Wiggins S. (eds.) Discursive research in practice: New approaches to psychology and interaction. Cambridge: Cambridge University Press; 2007: 31-49.

12. Fanon F. Black skin, white masks. Grove press; 2008.

13. Feinstein A. A History of Autism: Conversations with the Pioneers. Malden, MA: Wiley- Blackwell; 2010.

14. Goodley D. Disability studies: An interdisciplinary introduction. London: Sage; 2011.

15. Grue J. Disability and discourse analysis: Some topics and issues. Discourse \& Society. 2011; 22(5), 532-546.

16. Guilfoyle M. Storying unstoried experience in therapeutic practice. Journal of Constructivist Psychology. 2018; 31(1): 95-110. Available from: doi: 10.1080/10720537.2016.1266450.
17. Harper D. Discourse Analysis. In: Slade M. Priebe S. (eds.) Choosing Methods In Mental Health Research: Mental health research from theory to practice. London: Routledge; 2006: 132-146.

18. Hollway W. Jefferson T. Researching defended subjects with the free association narrative interviewing method. In: Cook JH. Bhattacharya S. Hardy H. (eds.) History of the social determinants of health: Global histories, contemporary debates. Hyderabad: Orient Black Swan; 2009: 296-315.

19. Janesick VJ. Oral History for the Qualitative Researcher: Choreographing the Story. Guilford Press; 2010.

20. Jefferson G. Glossary of transcript symbols with an introduction. In: Lerner GH. (ed.) Conversation analysis: Studies from the First Generation. Amsterdam: John Benjamins; 2004: 13-31.

21. Lester JN. Paulus T.M. Performative acts of autism. Discourse \& Society. 2012; 23(3): 259-273.

22. Lester JN. The discursive construction of autism: Contingent meanings of autism and therapeutic talk. Unpublished doctoral Theses, University of Tennessee, Knoxville, TN; 2011.

23. McAvoy J. From ideology to feeling: discourse, emotion, and an analytic synthesis. Qualitative Research in Psychology. 2015; 12(1): 22-33.

24. McGuire, A. War on Autism: On the Cultural Logic of Violence. United States: University of Michigan Press; 2016

25. Murray S. Representing Autism: Culture, Narrative, Fascination. Liverpool: Liverpool University Press; 2008.

26. Potter J. Representing reality: Discourse, rhetoric and social construction. London, UK: Sage; 1996.

27. Potter J. Wetherell M. Discourse Analysis. In: Smith J. Harre R. Langenhove LV (eds.) Rethinking Methods in Psychology. London: Sage; 1995: 80-92.

28. Rocque B. Science fictions: Figuring autism as threat and mystery in medico-therapeutic literature. Disability Studies Quarterly. 2010; 30(1). Available from: https://dsq-sds.org/article/ view/1064/1231 [Accessed 20th April 2018].

29. Rose N. The Psychological Complex. London: Routledge \& Kegan Paul; 1985.

30. Rose N. The Politics of Life Itself. Biomedicine, Power and Subjectivity in the Twenty-First Century. New Jersey: Princeton University Press; 2007.

31. Sacks H. On doing ‘being ordinary’. In: Atkinson JM. Heritage J. (eds.) Structures of social action: Studies in conversation analysis. Cambridge: Cambridge University Press; 1984: 413-429.

32. Shotter J. Conversational Realities: Constructing Life Through Language. London: Sage; 1993.

33. Tantam D. Can the world afford autistic spectrum disorder?: Nonverbal communication, asperger syndrome and the interbrain. Jessica Kingsley Publishers; 2009.

34. Thomson RG. Disability, identity, and representation: an introduction. In: Thomson RG (ed.) Extraordinary Bodies: Figuring Physical Disability in American Culture and Literature. New York: Columbia University Press; 1997: 5-18.

35. Turner B. Theoretical developments in the sociology of the body. Australian Cultural History. 1994; 13(1): 13-30.

36. Waltz M. Reading case studies of people with autistic spectrum disorders: A cultural studies approach to disability representation. Disability and Society. 2005; 20(5): 421-435.

37. Wetherell M. Positioning and interpretative repertoires: Conversation analysis and post-structuralism in dialogue. Discourse and Society. 1998; 9(3): 387-412.

38. Wiggins S. Discursive psychology: Theory, method and applications. London: Sage; 2017.

39. Yergeau M. Authoring Autism: On Rhetoric and Neurological Queerness. Durham and London: Duke University Press; 2018. 


\section{Appendix 1}

\section{Transcription Conventions}

The transcription conventions were adapted by Jefferson (2004)

$\uparrow$ Upward arrows represent marked rise in pitch.

$\downarrow$ Downward arrows represent a downward shift in pitch.

$><$ Text encased in greater than' and less than' symbols

is hearable as faster than

the surrounding speech.

$<>$ When turned greater than' and less than' symbols encase speech, the speech is

hearable as stretched or slower than the surrounding speech.

$=$ Equal signs at the end of a speaker's utterance and at the start of the next utterance represent the absence of a discernable gap.

[ ] Extended square brackets mark overlap between utterances.

(1.7) Numbers in parentheses indicate pauses.

A period with no number following (.) indicates a pause which is hearable, yet too short to

measure.

A column (:) symbol indicates that the world is pronounced through extensive brake

Underlined words (therapist) indicate that emphasis is placed on the specific spoken word or section

Bold letters (word) indicate that the word or phrase is talked in increased volume with regards to surrounding text.

/ slash indicates a full stop of talk 